\title{
Silver Lining and Hope in Relation with the Quality of Life in Adult Cancer Patients
}

\author{
Ms. Alvita de Souza ${ }^{1}$, Dr. Shanmukh V. Kamble ${ }^{2}$
}

\section{ABSTRACT}

The objective of this study was to find the impact of finding a Silver lining and Hope in sickness on the Quality of Life in Stage 1 and Stage 2 Cancer patients. The sample for the study consisted of 397 Cancer patients aged between 36 to 67 years (Male=156 \& Female= 241). The Silver Lining Scale, Adult Hope Scale and the Quality of Life for Adult Cancer Survivors were administered on the participants. Results indicated that Silver lining and Trait hope was a significant predictor in Quality of Life in Cancer Patients. The implication of this study is to improve the Quality of Life in patients by empowering them with the cognitive strategies of finding a Silver lining and enhancing Hope.

Keywords: Silver Lining, Hope, Quality of Life, Cancer Patients

"Relatively few people seek cures, but vast numbers of them are desirous of psychological services that can help them function more effectively in their everyday lives"- James Maddux

The chief killer diseases of today are heart diseases, cancer and violent death from accidents and homicides Fusch (1974). According to the current statistics of cancer in the United States by the year 2015, there will be an estimated 1,658,370 new cancer cases diagnosed and 589,430 cancer deaths in the US (Cancer facts and figures,2015). Cancer is a dreaded disease and ranks as the fourth cause of death in India (Panndda, 1982).

The news of acquiring the dreaded disease of cancer often results in an emotional turmoil in the individual. Research by Gallhorn et al (1953) indicates that an acute emotional shock such as the one received on the news of cancer results in the non coordination between the sympathetic and the parasympathetic nervous systems ultimately resulting in autonomic disorganization.

\footnotetext{
${ }^{1}$ Research Scholar, Karnatak University

${ }^{2}$ Associate Professor, Department of Psychology, Karnatak University

*Responding Author

(C) 2016 I A De Souza, S Kamble; licensee IJIP. This is an Open Access Research distributed under the terms of the Creative Commons Attribution License (http://creativecommons.org/licenses/by/2.0), which permits unrestricted use, distribution, and reproduction in any Medium, provided the original work is properly cited.
} 


\section{Silver Lining and Hope in Relation with the Quality of Life in Adult Cancer Patients}

Through the Clinical viewpoints, patients with cancer are predisposed to some psychiatric symptoms and mental disorders due to their life styles or disease conditions. These problems cause patients to deal with daily stress, feeling guilty, anxiety, dysphoric mood, and impaired social relations. Such problems would lead to serious mental disorders (Shabani et al, 2014).

However when a comparison was made through studies of meta-analysis showed no significant differences between cancer patients and the normal population with respect to anxiety and psychological distress. It was found that the cancer patients seemed to be significantly more depressed than normal healthy individuals. Compared with psychiatric patients, cancer patients were significantly less depressed, anxious, or distressed (Spiker et al, 1997). The cancer patients under therapy experience complications like anxiety, depression, and poor quality of life (Moghimi et al, 2014)

When adverse life events occur, people often suffer negative consequences for their mental health and well-being. More adversity has been associated with worse outcomes, implying that the absence of life adversity should be optimal. However, some theory and empirical evidence suggest that the experience of facing difficulties can also promote benefits in the form of greater propensity for resilience when dealing with subsequent stressful situations. Research demonstrates a U-shaped relationships between lifetime adversity exposure and mental health and well-being. It was found that a history of some lifetime adversity predicts better outcomes than not only a history of high adversity but also a history of no adversity. This has important implications for understanding how a life adversity can have benefits (Seery et al, 2011)

Depression is frequent in cancer patients also involving factors like deterioration of quality of life, difficulties communicating with carers, friends and family, an increased risk of suicide (Dauchy et al, 2013). Cancer detection always has a lot of stress and nervousness which, apart from physical injuries, will affect quality of life (Talepasand et al, 2013)

Knowledge of research Positive Psychology will help people avail of positive traits in them that help them cope with an illness. Adding to the research database also build the field of Positive Psychology. It involves the adopting of a new approach and set of values but also a new language for talking about human behavior. Strategies and techniques through research should be developed for enhancing the quality of lives as its applications are in the medical, educational, relational and social fields. Knowledge of its correlations and its impact on the quality of life, will be helpful to people and be an assistance in community centers, public and private schools, churches, and people's homes rather than in specialized facilities (Maddux,2007)

Positive psychology emphasizes goals, well-being, satisfaction, happiness, interpersonal skills, perseverance, talent, wisdom, and personal responsibility. It is concerned with understanding what makes life worth living, with helping people become more self-organizing and selfdirected, and with recognizing that "people and experiences are embedded in a social context" 
(Seligman \& Csikszentmihalyi, 2000). These principles offer a conception of psychological functioning helps to identifying and understanding human strengths and assets as to human weaknesses and deficits (Lopez \& Snyder, 2003).

More specifically, a Positive approach is concerned with understanding and enhancing subjective well-being and effective functioning as it is with alleviating subjective distress and maladaptive functioning. Positive psychological assessment will emphasise the evaluations of people's strengths and assets along with their weaknesses and deficiencies (Keyes \& Lopez, 2002)

More often than not, strategies and tactics for assessing strengths and assets will borrow from the strategies and tactics that have proven useful in assessing human weaknesses and deficiencies (Lopez et al., 2003). It is concerned not just with alleviating or preventing "suffering, death, pain, disability, or an important loss of freedom” (APA, 2000), but also with promoting health, happiness, physical fitness, pleasure, and personal fulfillment through the free pursuit of chosen and valued goals. It is a matter of vision and mission.

The Silver lining effect predicts that segregating a small gain from a larger loss results in greater psychological value than does integrating them into a smaller loss. Using a generic prospect theory value function, we formalize this effect and derive conditions under which it should occur. We show analytically that if the gain is smaller than a certain threshold, segregation is optimal. This threshold increases with the size of the loss and decreases with the degree of loss aversion of the decision maker. The silver lining effect is more likely to occur when (i) the gain is smaller (for a given loss), (ii) the loss is larger (for a given gain) (Johnson et al,2009)

Greater self-compassion and finding positives in adversity has consistently been associated with lower levels of depression and anxiety (Barnard \& Curry, 2011). These findings were supported by a recent study (MacBeth \& Gumley, 2012) which leads to a lesser level of depression, anxiety, and stress. In addition, a number of studies have found associations between finding silver linings and positive psychological qualities, such as happiness, optimism, wisdom, curiosity and exploration, personal initiative, and emotional intelligence (Heffernan, Griffin, McNulty, \& Fitzpatrick, 2010; Hollis-Walker \& Colosimo, 2011; Neff, Rude, \& Kirkpatrick, 2007).

The pervasive lack of articulated theory and the methodological inconsistency within and across the health care disciplines have resulted in the Quality of Life being equated with diverse constructs. Quality of Life thus refers to the functional ability of an individual with respect to subjective wellbeing and happiness across life dimensions of sickness, sex, pain, level of fatigue and life satisfaction. It includes the behavioral competencies needed to gain satisfaction in valued areas of life like happiness, perceived personal control, mortality of a disease, symptoms of psychological disturbance and physical illness (Stewart and King 1994). The Quality of life theory assumes that many additional benefits accrue individuals who find their happiness even in 
adversity. Orienting oneself to a good quality of life helps to boost confidence, optimism and self efficacy. It also entails sociability, prosocial behavior and effective coping with stress (King et al, 2004)

\section{DEFINING THE CONCEPTS}

Silver Lining- It refers to a positive consequence of illness that is realized. a sign of hope in an otherwise unfortunate or gloomy situation. It is often described as the ideation of a bright prospect in duration of an adverse situation or illness. It involves the replacing fear by a thought of optimism (Sodergren et al,2002)

Hope- can be defined as the sum of the mental will power and the way power that one has for goals. Willpower is the driving force in hopeful thinking. It taps the potential for action in a situation. Waypower reflects the mental plan that guides a hopeful thought and directs perception. It reflects a mental set that provides a special advantage when situations are adverse and weary (Snyder,2010)

Quality of Life-refers to the level of satisfaction that an individual derives from life as a feel good factor despite their health status and the subsequent ability to manage everyday life activities. It involves a positive outlook towards life the psychological wellbeing of an individual. (Salek and Avis,1999)

\section{METHOD}

\section{Sample and Procedure}

The correlation research design was used to investigate the relationship between the perception of Silver lining and Quality of life in cancer patients. The sample used for the study consisted of 397 cancer patients from Goa aged between 36-67 years (Male=156 \& Female= 241) The patients were chosen by availability sampling. The inclusion criteria was that the patients should be diagnosed with and be at Stage 1 and Stage 2 of Cancer and should have undergone treatment for the same. All participants received information sheets stating the purpose of the study and signed consent forms prior to participating in the study. Help was provided to the participants in the case they found any of the items difficult to comprehend. The results obtained were analyzed by SPSS 20 and used in the current study.

The researcher utilized 3 sets of standardized Psychological tests for data collection. A) The Silver lining questionnaire- Sodergren, S. C. \& Hyland, M. E. (1997) Although illness can be a distressing experience, some people who have or have had an illness talk about its positive aspects. This questionnaire asks the participants to think about this positive side of illness. There are 38 statements about the experience of being ill. Participants indicate how they agree or disagree with each of the items by using a 5-point rating scale that ranges from 5-strongly agree to 1-strongly disagree. B) The Adult Trait Hope scale- Snyder et al(1991)- This scale consists of 12 items and asks participants to indicate their level of hope from 1-Definitely false to 8- 
Definitely True. C) The Quality of life for Adult Cancer Survivors- Avis, N. E. Et al (2005)This questionnaire asks the participants to think about their quality of life after being diagnosed with cancer. It has 47 items. Participants indicate their answer from a scale ranging from 1-Never to 7-Always.

\section{RESULTS}

Ha1: There will exist a positive correlation between Silver lining and the Quality of Life in cancer patients

Table 1: Pearsons correlation coefficient among the Silver lining and the Quality of Life in Adult Cancer patients $(\mathrm{N}=397)$

\begin{tabular}{|l|l|l|}
\hline Measures & Silver Lining & Quality of Life \\
\hline Silver Lining & 1 & $.382^{* *}$ \\
\hline Mean & 94.48 & 252.74 \\
\hline SD & 16.49 & 34.46 \\
\hline
\end{tabular}

**significant at the 0.01 level *significant at the 0.05 level

The Pearson's coefficient of correlation was computed to measure the relationship between Silver lining and Quality of life in cancer patients. It was found that Silver Lining had a significant positive correlation with Quality of life $(r=.382, p=<0.01)$. The Mean and SD scores on Silver Lining ( $M=94.48$ \& SD=16.49) and Quality of Life ( $M=252.74$ \& SD=34.46) Thus the hypothesis that there will exist a positive correlation between Silver lining and the Quality of life in Cancer patients is proved.

Ha2: There will exist a positive correlation between hope and the quality of life in cancer patients

Table 2: Pearsons correlation coefficient among the Hope and the Quality of Life in Adult Cancer patients $(\mathrm{N}=397)$

\begin{tabular}{|l|l|l|}
\hline Measures & Hope & Quality of Life \\
\hline Hope & 1 & $.427^{* *}$ \\
\hline Mean & 51.31 & 252.74 \\
\hline SD & 7.75 & 34.46 \\
\hline
\end{tabular}

The Pearson's coefficient of correlation was computed to measure the relationship between Hope and Quality of life in cancer patients. It was found that Hope had a significant positive correlation with Quality of life $(r=.427, \mathrm{p}=<0.01)$. The Mean and SD scores on Adult Hope Scale (M=51.31 \& SD=7.75) and Quality of Life (M=252.74 \& SD=34.46). Thus the hypothesis that there will exist a positive correlation between Hope and the Quality of life in Cancer patients is proved. 
Ha3: There will exist a predictive value of Silver lining and Hope in relation to the Quality of Life in cancer patients

Table 3: Stepwise multiple regression analysis predicting the Quality of Life from Silver Lining and Hope $(\mathrm{N}=397)$

\begin{tabular}{|c|c|c|c|c|c|c|}
\hline Predictors & $\boldsymbol{\beta}$ & $\mathbf{R}$ & R Square & Adjusted R Square & t-value & $\mathbf{F}$ \\
\hline $\begin{array}{l}\text { 1.Silver } \\
\text { Lining } \\
\text { 2. Hope }\end{array}$ & $\begin{array}{l}0.156 \\
0.184\end{array}$ & .156 & .024 & .022 & $\begin{array}{l}4.45^{* *} \\
3.32 * *\end{array}$ & $9.825 * *$ \\
\hline
\end{tabular}

* *significant at the 0.01 level *significant at the 0.05 level

Table 2 showed that stepwise regression revealed a significant model of Quality of Life, $\mathrm{F}=9.825, \mathrm{p}=.000$, which explained $22 \%$ of the variance (Adjusted $\mathrm{R}^{2}=.22$ ). In the model, Silver Lining $(\beta=0.156), \mathrm{t}=4.45(\mathrm{p}<0.01)$ and Hope $(\beta=0.184), \mathrm{t}=3.32(\mathrm{p}<0.01)$ emerged as a significant predictor for quality of life. Thus the hypothesis that there will exist a predictive value of Silver lining and Hope in relation to the Quality of life in Cancer patients is proved.

\section{DISCUSSION}

The preliminary findings of this study revealed that Silver Lining had a significant positive correlation with Quality of life in Cancer Patients( $\mathrm{r}=.382, \mathrm{p}=<0.01)$. The second analysis revealed that Hope had a significant positive correlation with Quality of life $(r=.427, p=<0.01)$. The third analysis was carried out with a stepwise multiple regression analysis to find out if the variables of the silver lining and hope predicts quality of life in cancer patients. The variable contributed to $22 \%$ in predicting the Quality of Life which was found to be significant at the 0.01 level $(\mathrm{F}=9.825)$

These finding was supported by research conducted by Seery et al (2011) conducted studies on patients with chronic back pain and found that the experience of finding the positive aspects in this adversity promoted benefits in the form of greater propensity for resilience while dealing with the stressful situation. Finding the positive in an adversity has a U-shaped benefit with mental health and wellbeing. This finding was also supported by Croft, Dunn et al (2014) conducted a study on participants of adverse events. This research began with a checklist of adverse events including chronic illnesses. It was found that individuals who were currently struggling with adversity reported a diminished proclivity for savoring positive events; however the individuals who had dealt with adversity in a positive outlook in the past reported an elevated capacity for dealing with the adversity. Thus, the worst experiences in life may come with an eventual upside, by promoting the ability to appreciate life's small pleasures. 


\section{CONCLUSION}

Adversities of varying magnitudes impact the lives of each and every individual. One such adversity may come in the form of sickness. Acquiring the news of cancer and undergoing the turmoil of subsequent treatment can take a toll on the quality of life of the individual. However taking a positive approach like finding a Silver lining and maintaining Hope even in the worst adversity can bring about a better Quality of Life. Thus empowering the individual to face their current adversities.

\section{REFERENCES}

Aspinwall, L. G., \& MacNamara, A. (2005). Taking positive changes seriously: Toward a positive psychology of cancer survivorship and resilience. In Cancer (Vol. 104, pp. 2549-2556).

Casellas-Grau, A., Font, A., \& Vives, J. (2013). Positive psychology interventions in breast cancer. A systematic review. Psycho-Oncology. http://doi.org/10.1002/pon.3353

Croft, A., \& Dunn, W. (2014). From Tribulations to Appreciation: Experiencing Adversity in the Past Predicts Greater Savoring in the PresentSocial Psychological and Personality Science July 1, 2014 5: 511-516

Duckworth, A. L., Steen, T. A., \& Seligman, M. E. P. P. (2005). Positive psychology in clinical practice. Annual Review of Clinical Psychology, 1, 629-51. http://doi.org/10.1146/annurev.clinpsy.1.102803.144154

Ehde, D. M. (2010). Application of positive psychology to rehabilitation psychology. In Handbook of rehabilitation psychology (2nd) ed. (pp. 417-424). Retrieved from http://search.ebscohost.com/login.aspx?direct=true\&db=psyh\&AN=2009-19679029\&site $=$ ehost-live

Jarnebrant, P., Toubia, O., \& Johnson, E. (2009). The Silver Lining Effect: Formal Analysis and Experiments. Management Science, 55(11), 1832-1841. http://doi.org/10.1287/mnsc.1090.1076

Joseph, S., \& Wood, A. (2010). Assessment of positive functioning in clinical psychology: Theoretical and practical issues. Clinical Psychology Review. http://doi.org/10.1016/j.cpr.2010.01.002

Lopez, S. J. (2008). Positive psychology: exploring the best in people. Praeger perspectives. Retrieved from http://www.loc.gov/catdir/toc/ecip0813/2008010558.html

Maddux, J. E. (2008). Positive psychology and the illness ideology: Toward a positive clinical psychology. Applied Psychology, 57, 54-70. http://doi.org/10.1111/j.14640597.2008.00354.x

Miller, S. M., Sherman, A. C., \& Christensen, A. J. (2010). Introduction to special series: The great debate-evaluating the health implications of positive psychology. Annals of Behavioral Medicine. http://doi.org/10.1007/s12160-010-9173-9

Peterson, C. (2006). A primer in positive psychology. A primer in positive psychology. Retrieved from http://libezproxy.tamu.edu:2048/login?url=http://search.proquest.com/docview/621396351?accou 
ntid=7082 \nhttp://linkresolver.tamu.edu:9003/tamu?url_ver=Z39.882004\&rft_val_fmt=info:ofi/fmt:kev:mtx:book\&genre=book\&sid=ProQ:PsycINFO\&atitle $=\&$ title $=\mathrm{A}+$ primer + in

Seery, M. D. (2011). Resilience: A Silver Lining to Experiencing Adverse Life Events? Current Directions in Psychological Science, 20(6), 390-394. http://doi.org/10.1177/0963721411424740

Seligman, M. E. P., \& Csikszentmihalyi, M. (2000). Positive psychology - An introduction. American Psychologist, 55(1), 5-14. http://doi.org/10.1037//0003-066x.55.1.5

Sin, N. L., \& Lyubomirsky, S. (2009). Enhancing well-being and alleviating depressive symptoms with positive psychology interventions: A practice-friendly meta-analysis. Journal of Clinical Psychology, 65(5), 467-487. http://doi.org/10.1002/jclp.20593

Tan, S.-Y. (2006). Applied positive psychology: Putting positive psychology into practice. Journal of Psychology and Christianity, 25(1), 68-73. Retrieved from http://ezproxy.umsl.edu/login?url=http://search.ebscohost.com/login.aspx?direct=true\&d b=psyh\&AN=2006-04847-008\&site=ehost-live\&scope=site

Wood, A. M., \& Tarrier, N. (2010). Positive Clinical Psychology: A new vision and strategy for integrated research and practice. Clinical Psychology Review. http://doi.org/10.1016/j.cpr.2010.06.003

Yates, T. M., \& Masten, A. S. (2004). Fostering the Future: Resilience Theory and the Practice of Positive Psychology. In Positive Psychology in Practice (pp. 521-539). http://doi.org/10.1002/9780470939338.ch32 